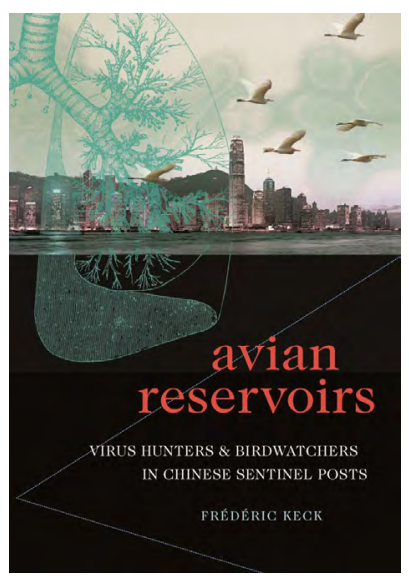

Avian Reservoirs: Virus Hunters and Birdwatchers in Chinese Sentinel Posts (Duke University Press 2020)

\section{Asian Reservoirs A Conversation with Frédéric Keck}

\author{
Mara BENADUSI \\ Andrea Enrico PIA
}

The Covid-19 pandemic has brought the whole world to its knees. Yet, this coronavirus is only the latest in a number of zoonosis events originating in different parts of the globe, and especially within Asia, over the last 20 years. For this reason virologists commonly refer to places like China, Hong Kong, or Singapore as reservoirs of potential viral threats. The combination of advanced logistic infrastructures, industrial farming, and the progressive disappearance of wild ecologies in these places arguably facilitates animal-to-human transmission of zoonotic diseases. In Avian Reservoirs: Virus Hunters and Birdwatchers in Chinese Sentinel Posts (Duke University Press 2020), Frédéric Keck challenges the idea of zoonosis as an Asian problem, and shows us how attending to the wild and domesticated behaviour and physiology of birds reveal the multiple and often contradictory ways in which virologists and citizen scientists make sense of epidemics and inform their policy advice.

Andrea Enrico Pia: Let's start from the end. All of us have been subjected to differently graded forms of sanitarian intervention for the past two or three months. Extremely coercive measures, including complete lockdowns, have been put in place globally to bring Covid-19 under control. The way in which these lockdown have been socialised, though, has brought to the fore the pastoral powers-to borrow one of the key analytics of Avian Reservoirs-of public shaming, surveillance, and mutual accusations in a concerted effort to curtail the infection through the micro-policing of individual behaviour. This has often occurred at the expense of investigating real sites of contagion, such as hospitals and shop-floors. In a way, public health-minded citizens have become the real 'sentinels' against the propagation of the virus. In your book, you analyse a different kind of 'sentinel'-birds-and varying ways of being alert to contamination that do not resort to pastoral power or coercion. Can you tell us a bit more about why the concept of the 'sentinel' is important for the study of pandemics? 
Frédéric Keck: Sentinels can be defined as devices to perceive early warning signals of an upcoming disaster. It is a military technology-sentinels are soldiers going to the frontline to raise the alarm when the enemy approaches-transferred to environmental concerns: there are sentinels for hurricanes, earthquakes, floods, species extinction, nuclear accidents, chemical pollution, and emerging infectious diseases. The sentinel perceives the threat before it can be measured, it makes visible the invisible signs of danger, it is attentive to the weak noises announcing a disaster. Non-human animals have been configured as sentinels because they are physiologically close to humans and more sensitive, such as chickens for bird flu or clams for chemical pollution. But we can conceive that robots or plants could be used as sentinels as well. In Avian Reservoirs, I argue that sentinel devices are cynegetic techniques-i.e. related to hunting-because they allow human experts to communicate with birds through images of viruses or numbers of species extinction, in the same way as shamans communicate with animals in hunting societies. By contrast with pastoral power, which is organised from above to decide which animal in the flock can be saved and which must be sacrificed, cynegetic power is horizontal and reversible: it starts from a shared vulnerability to environmental disasters, but also from a prey-predator relationship in a common habitat. For Covid-19, because of the failure of early warning signals in Europe, we had to use the costly techniques of lockdown to avoid deciding on triage and sacrifice, but now that the peak of the epidemic is behind us, sentinel devices are used to control the spread of the virus, for instance by detecting its prevalence in the sewerage system or training dogs to smell SARS-Cov2 in human tissues.

Mara Benadusi: In your book, you encourage us to see pathogens from the perspective of animals themselves. Now that several countries are moving towards a 'phase two' in response to the pandemic, a debate is emerging around how to 'live with' the virus. It is on this phrase, 'live with', in the sense of coexistence, that I would ask you to dwell a bit more. How can the current pandemic help us to reframe concepts of causality and relatedness, reflecting different modes of coexistence between humans and viruses, humans and animals, and humans and the environment more generally? Is it possible to imagine a phase of real 'coexistence' in this broader sense and how could taking the perspective of a bat-or a pangolin-help with making it more viable?

FK: Responses to pandemic in 'phase one' rely on a simple concept of causality: identify the chains of transmission to predict the number of casualties and reduce this number by cutting the chain of transmission. But in 'phase two', we realise that the causality is more complex: if we shut down wet markets in central China, animals trafficked for the growing demand for materials used in Chinese traditional medicine will be smuggled, 
and viruses transmitted by bats will take another road. So we need to prepare for future pandemics coming from animals with a much broader view of our interactions with them, and of our interactions with microbes that cause immunological panics when viruses jump from wild animals. Taking the perspective of bats-or pangolins, or whatever animal has been the intermediary vector in Chinese wet markets, or dromedary camels in the transmission of MERS-Cov-is how virologists simulate the spread of future pandemics, by imagining methods of transmission that have not occurred yet but that could have catastrophic consequences. This is the reason why I argue that preparedness relies on a holistic view of relations between humans, animals, and microbes, while precaution relies on a much more linear view. This is the ambivalence of the notion of animal reservoir: either as something to know and imagine, or as something to control and eradicate.

AEP: Let me turn your attention to the People's Republic of China for a moment. In the West, China has been accused of 'coronavirus diplomacy'-the political sleight of hand of hiding the country's role in the early spreading of Covid-19 by overplaying its commitment to international medical aid and cooperation. In the attempt to control the narrative of the post-pandemic world to come, many are now commenting, often in flatly racist terms, on the supposed Asian propensity to live in what you call 'spaces of contagion'-sites where humans and animals live in too close proximity with one another. In your research on the H5N1 avian flu, for instance, you visited many such 'wet', 'poultry', and 'bird' markets. Are these special places to consider when thinking about the origin of the current pandemic, or do they represent just one of the sites along a food supply chain where (potentially zoonotic) encounters between humans and animals are staged?

FK: Wet markets are very special places for social anthropologists because they are sites of intense relations between humans, animals, and microbes. I spent a lot of time in wet markets in Hong Kong-'wet' refers to the fact that markets must be cleaned every day to avoid contamination-to understand why consumers want to buy a chicken or a fish 'fresh' to carry back home after it has been killed, and how retailers perceive such a risky activity as exposing themselves daily to the slaughter of potentially infected chickens. I also followed Buddhist practitioners who bought birds or fish in wet markets to release them as a gesture producing 'merits' (放生), and who were criticised by environmentalists because the release often led to the death of animals. There is so much life and death in these markets that they are perfect sites for the observation of biopolitics in the making. In my next ethnographic project, I will study how the regulation of these wet markets in Hong Kong and Singapore over the last 20 years will be applied in central China. China wants to appear as a 'clean state' after the 
pandemic, and yet people will continue buying food in these wet markets because they don't trust the safety and quality of meat in supermarkets.

MB: One of your main interlocutors in Asian Reservoirs is Malik Peiris from Sri Lanka, Chair Professor at the Department of Microbiology at the University of Hong Kong and Scientific Director of the HKU-Pasteur Research Centre at Hong Kong. Professor Peiris is a renowned virologist and is most notable for being the first person to isolate the SARS virus. In the West, experts' handling of the Covid-19 pandemic has been largely criticised for its mixed messages and internecine animosity. Can you tell us more about the role played by 'experts' from Asia in the 'hunt' for viruses? Has their scientific authority in managing viral outbreaks ever been subjected to similar criticism? Could you help us reconstruct a genealogy of these Asian professionals and the political reception of their work leading up to the current pandemic?

FK: Virologists in Hong Kong became heroes after SARS because they helped society survive an epidemic that was about to collapse the economy. The fear of SARS-Cov2 can only be explained as a global extension of the fear experienced by Hong Kong society during the SARS crisis: a liberal economy that relies on the circulation of commodities and persons can collapse if an infectious agent blocks the chain of production. Virologists in Hong Kong acted as mediators in the sense of Bruno Latour-they attenuated the violent tension between production, circulation, and consumption by controlling the mutations of infectious agents. In that sense, I argue that they worked as shamans in hunting societies. Virologists tamed wild animals by transforming them into sentinels so that they would not take 'revenge' against humans. Now this shamanicheroic role in the chains of domestication is also configured by the techniques of the global war against terrorism. SARS was conceived as Asia's 9/11, the virus hijacking cells and taking planes to travel around the globe, causing panic after circulating silently. SARS heroes are controlling 'nature as a bioterrorist threat': that is why there is so much consensus around their role in preparing Hong Kong for future pandemics. By contrast, virologists in France have been caught in the traps of the precautionary principle. Is the government doing too much or too little? Do we have enough masks, vaccines, drugs, tests to protect the population? The Hong Kong government does not face these questions because it is rich and liberal. The only question it has to face is the following: is the government going to protect us from a Chinese invasion? As I show in my book, SARS heroes answered this question through the sophisticated language of viruses. 
AEP: In your book, you spend considerable time thinking about the categories of preparedness and prevention. From animal husbandry to birdwatching, from the study of viruses to the stockpiling of vaccines, societal-wide anticipation of future pandemics is key to responsiveness to outbreaks. In this sense, Covid-19 has thrown the 'unpreparedness' of Western countries into stark relief and shown the extent to which Western societies and economies may have to change to accommodate the threat of future epidemics. A debate is now raging between those interested in only minimally tweaking our current system to preserve the usual paths of capitalist accumulation and those who see in a 'pandemic shock' an unprecedented opportunity to consolidate the infrastructure of data-driven capitalism. Lastly, environmental justice campaigners wish this crisis could build momentum towards changing our dysfunctional relationship with the wild and the non-human. What lesson about 'being prepared' is there to be learnt from the Chinese 'sentinel' posts you have studied?

FK: The anthropologist Andrew Lakoff has taught us that when scenarios of preparedness meet the reality of disasters, we discover that we have always been unprepared. The lack of preparedness is precisely the motor that drives contingency planners to put more effort into imagining future disasters. What interests me is how these global scenarios are implemented in different locations based on various relations between humans and non-humans. In China, the fear of a pandemic was oriented less by the anticipation of a bioterrorist attack than by the fear of the emergence of a flu virus in poultry farms or wet markets; a pandemic was not conceptualised as a sign of godly apocalypse, but rather as a transformation in the heavenly mandate. The idea of being unprepared or that one may fail to perceive early warning signals of disasters takes on different meanings if one thinks that 'Nature' behaves like God, that is as an essence capable of talking to you directly, or if it is conceived of as an interpretable force that can be understood through its indirect forms of mutation. When I worked with virologists and ornithologists, I studied their understanding of a 'false alarm'. This could either mean that their target was wrongly interpreted as a vector of a potential epidemic, or that signs of an impending 'spill-over' were not leading to the right kind of prevention and mitigation response. In that sense, I was interested to see how Chinese societies perceived questions of environmental justice without sharing the Western theological separation between nature and culture and based on a different ontology of early warning signals, or sentinels.

MB: Following on from the last question, I wanted to ask your opinion about the social techniques of anticipation we encounter in your book. We are now witnessing a flurry of speculation relative to how to anticipate hypothetical future outbreaks and thus envision consequential public measures. However, this enormous effort of anticipation is not a neutral process. It distributes unequally the capabilities required by social actors to effectively influence their future. In circumstances of extreme uncertainty, 
such as those described in your book, the question is not only whose life is to be protected', but also 'what form of life we abandon or let die'. In your experience, what is the role assumed by pandemics in shaping the ways we think about our future as a society?

FK: This is another way to raise the question of social and environmental justice in the time of pandemics, and how preparing for future pandemics will allow us to build more solidarity and equity, or lead us to more competition, looting, and violence. I think that the first virtue of pandemic preparedness is to force us to include animals in the concern for vulnerability and care in a world we have transformed and damaged-call it the Anthropocene, if geologists agree. But of course, this is not a step forward if it results in us sacrificing some parts of the human population to meet the demands of preparedness. However, I don't think we have to make a choice between protecting humans and animals, and choosing which lives should be protected in a situation of emergency. This is one of the effects of the distinction between pastoral power and cynegetic power. Pastoral power is ready to sacrifice some parts of the flock for the wellbeing of the whole; cynegetic power takes the perspective of all living beings in a predatory situation, and death occurs almost as an accident that shouldn't be talked about. Preparedness is violent, the world in which we are entering is more favourable to predatory relations than to pastoral care, but hunting societies were more respectful of their environment, and taking their perspective might help us to think about the ecological challenges we have to face. 
This text is taken from Made in China Journal: Volume 5, Issue 2, 2020 , edited by Ivan Franceschini and Nicholas Loubere, published 2020 by ANU Press, The Australian National University, Canberra, Australia.

doi.org/10.22459/MIC.05.02.2020.25 